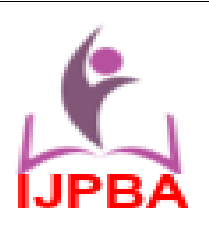

\author{
Contents lists available at www.ijpba.in \\ International Journal of Pharmaceutical and Biological Science Archive \\ PubMed (National Library of Medicine ID: 101738825) \\ Index Copernicus Value 2017: 71.80
}

Volume 7 Issue 5; September-October; 2019; Page No. 23-27

\title{
PHARMACOKINETICS OF INH AND PZA IN MDR-TB: A REVIEW
}

\section{S. Ramya ${ }^{1}$, S. Shanmugam ${ }^{2}$}

${ }^{1}$ M.Phil. Research Scholar, Department of Biochemistry, Asan Memorial College of Arts and Science (affiliated to the University of Madras) Velachery-Tambaram Road, Jaladampet, Chennai-600100, Tamilnadu , India

${ }^{2}$ Associated Professor, Department of Biochemistry, Asan Memorial College of Arts and Science (Affiliated to the University of Madras) Velachery-Tambaram Road, Jaladampet, Chennai-600100, Tamilnadu , India

Conflicts of Interest: Nil

Corresponding author: S. Ramya

\section{ABSTRACT}

Tuberculosis remains a leading cause of morbidity and mortality in developing countries, including india. Isoniazid and pyrazinamide are powerful drugs administered as the First line and second line Anti-TB drugs in Tuberculosis affected patient. It plays a key role in shortening the TB therapy. Isoniazid (INH), and pyrazinamide (PZA) are the main drugs for the treatment of tuberculosis (TB). Mycobacterium tuberculosis is responsible for causing tuberculosis can acquire multiple drug resistance (MDR) by not responding to the most powerful anti-TB agents. The complications of drug resistance in TB elevates the some of the risk factors like inadequate treatment compliance, noncompliance of the patients to the treatment. Pharmacokinetics provides a basic time course of drugs and their effects in the body. These pharmacokinetic processes referred to as ADME.

Key words Isoniazid, Pyrazinamide, MDR, ADME, TB

\section{INTRODUCTION}

Tuberculosis is an infectious disease caused by Mycobacterium species (M. tuberculosis in humans and $M$. bovis in cattle). The mortality rate is more higher. Tuberculosis is next to AIDS. Pharmacokinetics gives a mathematical basis to assess the time of drug interaction and their effects in the body. It enables the following processes: Absorption, Distribution, Metabolism, and Excretion. These pharmacokinetic referred to as ADME [1]; determine the drug concentration in the body when medicines are recommended. A fundamental understanding of these parameters is required to design an appropriate drug regimen for a patient $[2,3]$. Tuberculosis (TB) is one of the increasing causes of death worldwide [4] The number of reported MDR-TB cases has been leading in recent years [5]

Adsorption: Absorption is the process of a substance entering the blood circulation. Drug substances can enter the body via gastrointestinal tract, lung or skin, and they are absorbed. The gastrointestinal tract is the most important of site of absorption, it is affected by several factors such as physicochemical parameters of the drug, gastrointestinal motility, drug concentration at the site of absorption [6]
Distribution: Distribution describes the reversible transfer of drug from location to location within the body. The distribution of a drug is involved by factors such as lipid-solubility [7], concentration in plasma and in various tissues are binding to plasma, transport the proteins and tissues.

Metabolism: Metabolism is the process of irreversible transformation of parent compounds into daughter metabolites. The major site of metabolism occur in the body is the liver [8] There are many factors that influence drug metabolism including route of administration, dose, genetics, disease state, and metabolic activity[9]

Excretion: Excretion is the process of eliminating the drug and other toxic substances from the body. Most of the drugs in the body are eliminated through the urine. Substances with low lipid solubility such as polar metabolites are excreted efficiently [10].

Isoniazid: Isoniazid (also, Nicotinic Acid Hydrazide, INH or $\mathrm{H}$ ) is one of the drug for first-line treatment of tuberculosis along with Rifampicin and Pyrazinamide. It functions are block the production of Mycolic Acid, an essential cell wall component in the tuberculosis bacterium [11] [12]. Mycolic acid confers the bacterium with resistance to chemical damage and dehydration, and prevents the effective activity of hydrophobic antibiotics. In 
addition, mycolic acid allows the bacterium to grow on macrophages, effectively hiding it from the host's immune system. These are the reasons vital for the selection of mycolic acid as a drug target. They circulate in the bloodstream, the isoniazid prodrug is activated via a bacterial catalaseperoxidase enzyme, encoded by KatG gene [13]. Action of isoniazid is most significance in the first week of drug administration as it acts on rapidly multiplying bacteria. On slow growing bacteria, it acts as a bacteriostatic agent. The adverse effects of Isoniazid may result in discontinuation of treatment in some cases. The side effects can be listed astoxic, idiosyncratic and hypersensitivity reactions. Many toxic reactions are peripheral neuropathies at conventional dosage and seizures from overdosage. Idiosyncratic reactions are $\mathrm{INH}-$ induced lupus erythematosus, rheumatic-like syndromes and other hematologic disorders. Hypersensitivity reactions to isoniazid include hepatitis, dermatitis, fever, and haemolytic anaemia [14]. If the Mycobacterial strain is resistant to low dosage of $\mathrm{INH}(300 \mathrm{mg} /$ day $)$ in primary therapy, then a higher dosage $(1-1.5 \mathrm{~g} /$ day $)$ is administered to overcome the resistance. This high dosage of INH in the re-treatment of drug-resistant tuberculosis has been caculated in clinical trials [15].

Pyrazinamide: Pyrazinamide is a prodrug converted to its active form, pyrazinoic acid, by hepatic microsomal deamidase [16] and is active against dumbfounded and semi dumbfounded Mycobacterium tuberculosis bacilli, especially in acidic environments [17][18]. It is currently part of a four-drug fixed-dose combination (FDC), which includes isoniazid, ethambutol, and rifampin, an inducer of a number of cytochrome $P 450$ enzymes via the pregnane $X$ receptor (PXR) [19]. Pyrazinamide is currently being considered as a drug in tuberculosis (TB) treatment regimens [20-22], including for multidrug-resistant tuberculosis (MDR-TB).

Interest in the drug derives from its potent sterilizing activity, which confers the ability to shorten treatment duration. Pyrazinamide exposures have been correlated with favorable treatment outcomes in patients on standard doses[20],[23-28] . A pyrazinamide area under the concentration-time curve from 0 to $24 \mathrm{~h}\left(\mathrm{AUC}_{0-24}\right)$ of at least $363 \mathrm{mg} \cdot \mathrm{h} /$ liter has been associated with long-term TB treatment outcomes among patients with drug-susceptible TB and could be targeted for treatment optimization[20]. The current recommended weight-adjusted daily dose of pyrazinamide for treatment of drug-susceptible TB is approximately 25 (range, 20 to 30 ) $\mathrm{mg} / \mathrm{kg}$ of body weight[29], while that for treatment of MDR-TB is about 35 (range, 30 to 40 ) $\mathrm{mg} / \mathrm{kg}$ [30]. Doses higher than those currently recommended may result in high levels of 5-hydroxypyrazinoic acid, which is responsible for pyrazinamide induced hepatotoxicity [31]. On the other hand, there exist discrepancies in exposure between the weight bands; patients in the lower weight bands achieve lower drug exposures [32,33].

Despite interest in pyrazinamide, relatively few studies have described its pharmacokinetics (PK) longitudinally [34-37]. We previously reported PK exposures of pyrazinamide in this cohort of HIV/TBcoinfected patients [32]. Here, we use a population modeling approach to describe changes in PK parameters during the first month of treatment and identify other factors affecting the PK. We then used parameter estimates of the final model to simulate exposures associated with a range of feasible doses for treatment of drug-susceptible TB and MDR-TB.

MDR-TB: It is a condition in which mycobacterium tuberculi develops resistance to Isoniazid and Rifampicin, the two most effective first line anti-TB medicines. Patients with Multi Drug-Resistant Tuberculosis (MDR-TB) require treatment with second-line treatment, these are more complex than those used to treat patients without drugresistant TB [38]. The diagnosis of MDR-TB is by per- forming drug sensitivity tests (DST) on the isolates. DST data can also be used to identify the drug regimen. Second-line anti-tuberculosis drugs are less effective than first-line drugs and are known to cause adverse reac- tions more frequently. This class of anti-tuberculosis drugs includes para-aminosalicylic acid (PAS), amikacin, capreomycine, thionamide and cycloserine. New drugs such as rifapentine, levofloxacin, gatifloxacin and mox- ifloxacin have not yet been categorized. A retrospective study in Hong Kong compared the efficacy of two flu- oroquinolones- Levofloxacin and Ofloxacin in the treatment of MDR-TB. They administered these drugs along with accompanying second-line drugs and found that Levofloxacin had a $90.0 \%$ overall success rate as compared to $79.7 \%$ success rate of Ofloxacin [39].

\section{Conclusion:}

It is necessary to obtain human pharmacokinetic information about the drug of isoniazid and 
pyrazinamide in MDR-TB. Clinical pharmacokinetic studies are performed to examine the absorption, distribution, metabolism, and excretion of an investigational drug.This study will provide information on the pharmacokinetics profile INH\&PZA drugs in MDR-TB patients. Not only regarding tuberculosis, but also in relation to other microbial and infectious diseases, resistance towards antibiotics results in treatment failures, advancing of disease and infections. So, treatment should be directed towards using drugs which either overwhelm the resistance of organisms towards antibiotics or improve the benefits of other anti-TB drugs. Resistance repression is explained as one medication involve the resistance to another, but not one drug involve the resistance to itself. By taking appropriate measures and strictly following the therapy, the MDR-TB might be suppressed to a greater area.

\section{REFERENCE}

1. Jake J (2004) Thiessen: Chapter 8: Bioavailability and Bioequivalence. In The IUPHAR Compendium of Basic Principles for Pharmacological Research in Humans. (Ed's P. du Souich, M. Orme and S. Erill) IUPHAR 55-66.

2. Soraya Dhillon and Kiren Gill Basic pharmacokinetics. Clinical pharmacokinetics sample chapter 1-43.

3. Faruk Khan MO, Deimling MJ, Philip A (2011) Medicinal chemistry and the pharmacy curriculum. Am J Pharm Educ 10: 161.

4. Eker, B., Ortmann, J., Migliori, G.B., Sotgiu, G., Muettcrlcin, R., Centis, R., et al. (2008) Multidrug- and Extensively Drug-Resistant Tuberculosis, Germany. Emer ging Infectious D iseases , 14, 1700-1706. https://doi.org/10.3201/eid1411.080729

5. World Health Organization (2014) Global Tuberculosis Report 2014. Geneva.

6. Role of Pharmacokinetic Studies in Drug Discovery Nishant Toomula1*, Sathish Kumar D2, Arun Kumar3 and Phaneendra M1 Nishant et al., J Bioequiv Availab 2011, 3:11 DOI: 10.4172/jbb.1000097

7. Gabizon A, Amitay Y, Tzemach D, Gorin J, Shmeeda $H$, et al. (2011) Therapeutic efficacy of a lipid-based prodrug of mitomycin $\mathrm{C}$ in pegylated liposomes: Studies with human gastro-entero-pancreatic ectopic tumor models. J Control Release.

8. Chandrani gunaratna (2000) Drug metabolism and pharmacokinetics in drug discovery: A
Primer For Bioanalytical Chemists, Part II. Current seperations 19: 87-92.

9. Bienenstock J, Collins S (2010) 99th Dahlem conference on infection, inflammation and chronic inflammatory disorders: psychoneuroimmunology and the intestinal microbiota: clinical observations and basic mechanisms. Clin Exp Immunol 160: 85-91.

10. Carrillo Norte JA (2011) Pharmacokinetic process: does the site of drug action? Excretion of drugs. Rev Enferm. Sep;34: 24-31

11. Lei, B.F. and Wei, C.-J. (2000) Action Mechanism of Antitubercular Isoniazid. The Journal of Biological Chemistry, 275, 25202526. http://dx.doi.org/10.1074/jbc.275.4.2520

12. Vilchèze, C., Morbidoni, H.R., Weisbrod, T.R., Iwamoto, H., Kuo, M., Sacchettini, J.C. and Jacobs, W.R. (2000) Inactivation of the inhAEncoded Fatty Acid Synthase II (FASII) EnoylAcyl Carrier Protein Reductase Induces Accumulation of the FASI End Products and Cell Lysis of Mycobacterium smegmatis. Journal of Bacteriology, 182, 4059-4067. http://dx.doi.org/10.1128/JB.182.14.40594067.2000

13. Whitney, J.B. and Wainberg, M.A. (2002) Isoniazid, The Frontline of Resistance in Mycobacterium tuberculosis. McGill Journal of Medicine, 6, 114-123

14. Goldman, A.L. and Braman, S.S. (1972) Isoniazid: A Review with Emphasis on Adverse Effects. Chest, 62, 71-77. http://dx.doi.org/10.1378/chest.62.1.71

15. Moulding, T.S. (1981) Should Isoniazid Be Used in Retreatment of Tuberculosis Despite Acquired Isoniazid Resistance? The American Review of Respiratory Disease, 123, 262.

16. Konno K, Feldmann FM, McDermott W. 1967. Pyrazinamide susceptibility and amidase activity of tubercle bacilli. Am Rev Respir Dis 95:461- 469.

17. Mitchison DA. 1985. The action of antituberculosis drugs in short-course chemotherapy. Tubercle 66:219 -225 . https://doi.org/10.1016/0041-3879 (85)900406.

18. Steele MA, Des Prez RM. 1988. The role of pyrazinamide in tuberculosis chemotherapy. Chest 94:845- 850. https://doi.org/10.1378/chest.94.4 .845.

19. Chen J, Raymond K. 2006. Roles of rifampicin in drug-drug interactions: underlying molecular 
mechanisms involving the nuclear pregnane $X$ receptor. Ann Clin Microbiol Antimicrob 5:3.

20. Pasipanodya JG, Mcllleron H, Burger A, Wash PA, Smith P, Gumbo T. 2013. Serum drug concentrations predictive of pulmonary tuberculosis outcomes. J Infect Dis 208:1464 1473. https://doi.org/10.1093/infdis/ jit352.

21. Mitchison DA, Fourie PB. 2010. The near future: improving the activity of rifamycins and pyrazinamide. Tuberculosis 90:177-181. https://doi.org/ 10.1016/j.tube.2010.03.005.

22. Diacon $A H$, Dawson $R$, von Groote-Bidlingmaier F, Symons G, Venter A, Donald PR, van Niekerk C, Everitt D, Winter $H$, Becker P, Mendel CM, Spigelman MK. 2012. 14-day bactericidal activity of PA-824, bedaquiline, pyrazinamide, and moxifloxacin combinations: a randomised trial. Lancet 380:986 -993. https://doi.org/10.1016/S01406736(12)61080-0.

23. Zhang Y, Mitchison D. 2003. The curious characteristics of pyrazinamide: a review. Int J Tuberc Lung Dis 7:6 -21.

24. Heifets L, Lindholm-Levy P. 1992. Pyrazinamide sterilizing activity in vitro against semidormant Mycobacterium tuberculosis bacterial populations. Am Rev Respir Dis 145:12231225. https://doi.org/10.1164/ajrccm/145.5 .1223.

25. Mitchison DA. 2005. The diagnosis and therapy of tuberculosis during the past 100 years. Am J Respir Crit Care Med 171:699 -706. https://doi .org/10.1164/rccm.200411-16030E.

26. Chideya $S$, Winston $C A$, Peloquin $C A$, Bradford WZ, Hopewell PC, Wells $C D$, Reingold $A L$, Kenyon TA, Moeti TL, Tappero JW. 2009. Isoniazid, rifampin, ethambutol, and pyrazinamide pharmacokinetics and treatment outcomes among a predominantly HIVinfected cohort of adults with tuberculosis from Botswana. Clin Infect Dis 48:1685-1694. https:// doi.org/10.1086/599040.

27. Chigutsa E, Pasipanodya JG, Visser ME, van Helden PD, Smith PJ, Sirgel FA, Gumbo T, Mcllleron H. 2015. Imp act of nonlinear interactions of

pharmacokinetics and MICs on sputum bacillary kill rates as a marker of sterilizing effect in tuberculosis. Antimicrob Agents Chemother 59: $38 \quad$ - 45. https://doi.org/10.1128/AAC.03931-14.

28. Gumbo $T$, Chigutsa $E$, Pasipanodya J, Visser $M$, van Helden PD, Sirgel FA, Mcllleron H. 2014. The pyrazinamide susceptibility breakpoint above which combination therapy fails. J Antimicrob Chemother 69: $2420-2425$. https://doi.org/10.1093/jac/dku136.

29. World Health Organization. 2003. Treatment of tuberculosis: guidelines for national programmes, 3rd ed. WHO/CDS/TB/2003.313. World Health Organization, Geneva, Switzerland.

30. World Health Organization. 2009. Management of MDR-TB: a field guide. A companion document to guidelines for the programmatic management of drug-resistant tuberculosis. WHO/HTM/TB/2008.402a. World Health Organization, Geneva, Switzerland.

31. Shih T-Y, Pai C-Y, Yang P, Chang W-L, Wang NC, Hu OY-P. 2013. A novel mechanism underlies the hepatotoxicity of pyrazinamide. Antimicrob Agents Chemother 57:1685-1690. https://doi.org/10.1128/AAC.01866-12.

32. Mcllleron $H$, Rustomjee $R$, Vahedi $M$, Mthiyane T, Denti P, Connolly C, Rida W, Pym A, Smith PJ, Onyebujoh PC. 2012. Reduced antituberculosis drug concentrations in HIVinfected patients who are men or have low weight: implications for international dosing guidelines. Antimicrob Agents Chemother 56:3232-3238.

https://doi.org/10.1128/AAC.05526-11.

33. Sahota T, Della Pasqua O. 2012. Feasibility of a fixed-dose regimen of pyrazinamide and its impact on systemic drug exposure and liver safety in patients with tuberculosis. Antimicrob Agents Chemother 56: 5442-5449. https://doi.org/10.1128/AAC.05988-11.

34. Wilkins JJ, Langdon G, Mcllleron H, Pillai GC, Smith PJ, Simonsson US. 2006. Variability in the population pharmacokinetics of pyrazinamide in South African tuberculosis patients. Eur J Clin Pharmacol 62:727-735. https://doi.org/10.1007/s00228-006-0141-z.

35. Chigutsa E, Mcilleron H, Holford NHG. 2010. Parallel first order and mixed order elimination of pyrazinamide in South African patients with tuberculosis. Abstr Pop Approach Group Eur Meeting, abstr 1496.

36. Zhu $M$, Starke JR, Burman WJ, Steiner $P$, Stambaugh JJ, Ashkin D, Bulpitt AE, Berning SE, Peloquin CA. 2002. Population pharmacokinetic modeling of pyrazinamide in children and adults with tuberculosis. Pharmacotherapy 22:686 - 695.

37. Peloquin CA, Bulpitt AE, Jaresko GS, Jelliffe RW, James GT, Nix DE. 1998. Pharmacokinetics of pyrazinamide under fasting conditions, with 
S. Ramya et al, Journal of Pharmaceutical and Biological Science Archive

food, and with antacids. Pharmacotherapy 18:1205-1211.

38. James M, Cesar UG, David MAJ (2015) Multidrug resistant tuberculosis. BMJ. 350: 882.

39. Yew, W.W., Chan, C.K., Leung, C.C., Chau, C.H., Tam, C.M., Wong, P.C. and Lee, J. (2003)
Comparative Roles of Levofloxacin and Ofloxacin in the Treatment of MultidrugResistant Tuberculosis: Preliminary Results of a Retrospective Study From Hong Kong. Chest, 124,

1476-1481. http://dx.doi.org/10.1378/chest.124.4.1476. 